64

\title{
Growth Factors G-CSF and GM-CSF: Clinical Options
}

\author{
Thomas Hartung, Sonja von Aulock, and Albrecht Wendel
}

The body's immediate response to bacterial infection becomes clinically evident as an inflammatory reaction accompanied by an acute-phase response in the liver and hyperthermia. Activation of the immune system must be counterregulated to curb these processes and to prevent (or at least minimize) damage to the host tissue. The major part of this intricate regulation is performed by the cytokine mediator network, a relay of glycoprotein signals that first activate proliferation and host defense functions of immune cells and then control the return to a state of readiness when the infection is under control.

Septic shock encompasses fulminant, and self-destructive activation of the defense system that is now understood as a systemic inflammatory reaction followed by multiple organ failure. This extreme activation of the nonspecific immune system is followed, provided the patient can be stabilized by intensive medical care, by corresponding massive counterregulation. The patient, whose immune system is exhausted, is left almost defenseless in a state termed immune paralysis, or anergy. A patient in this state is particularly susceptible to lifethreatening secondary infections.

Granulocyte (G-CSF) and granulocyte/macrophage colonystimulating factors (GM-CSF) (Table 64.1), central mediators of the endogenous response to infection and inflammation, have been cloned and are commercially available in forms approved for clinical use (Table 64.2). Both stimulate the proliferation and release of immune cells from the bone marrow, and so they were originally approved for the treatment of leukopenia. G-CSF, when given prophylactically or as substitution in situations of deficiency, has also been attributed with improved host defense paired with antiinflammatory effects. GM-CSF, on the other hand, is considered a potent immunostimulator and proinflammatory agent.

Evidence from many animal studies and some clinical studies suggests that prophylactic treatment with G-CSF at the time a risk can be anticipated, such as before an operation, may offer protection from infections and lower the incidence of sepsis. GM-CSF therapy may find a place in reactivating the immune system of patients in a state of immune paralysis following septic shock, thercby reinforcing the patients' impaired defense system against secondary infections. (See Table 64.3 for approved and experimental indications.)

\section{G-CSF}

\section{Endogenous G-CSF Response to Infection}

The glycoprotein G-CSF is present at low concentrations (around $25 \mathrm{pg} / \mathrm{ml}$ ) in the serum of healthy volunteers. ${ }^{1}$ A significant increase in G-CSF secretion may be detected during the acute phase of a bacterial infection. ${ }^{4-6}$ Patients may have peak concentrations as high as $200 \mathrm{ng} / \mathrm{ml}$ at the onset of septic shock. ${ }^{7}$ These levels decrease significantly within a few days in survivors, but in nonsurviving sepsis patients the G-CSF levels remain persistently elevated. ${ }^{89}$ Furthermore, patients who do not respond to infection with increased G-CSF production have a worse prognosis than patients who respond with G-CSF production. ${ }^{10}$ These studies showed that patients with the best outcome are those who are able to respond appropriately to an infectious agent by increasing G-CSF levels and then decreasing them upon resolution of the infection. However, in patients with a fatal outcome, G-CSF levels tend to remain elevated, indicating an inability of the host to respond to circulating G-CSF, continued signaling for G-CSF production, or failure of the host to mount a sufficient G-CSF response. ${ }^{11}$ The observation that injection of pharmacologic doses of G-CSF $(10 \mu \mathrm{g} / \mathrm{kg})$ into healthy volunteers elevated the serum G-CSF to levels in the upper range of those reached by endogenous production during infection ${ }^{12}$ supports the hypothesis that administration of G-CSF under the conditions discussed above may be beneficial to the host by increasing or accelerating the response to infection.

\section{Role of G-CSF in the Cellular Immune System}

The central role of endogenous G-CSF lies in the maintenance and control of granulopoiesis, which is essential for efficient host defense, as demonstrated in knockout mice. ${ }^{13}$ or in normal mice injected with anti-murine G-CSF antiserum. ${ }^{14}$ Both sets of mice were severely neutropenic and unable to recruit additional 
TABLE 64.1. Common Abbreviations and Synonyms for G-CSF and GM-CSF.

\begin{tabular}{ll}
\hline Abbreviation & \multicolumn{1}{c}{ Synonym } \\
\hline G-CSF, CSF-G & Granulocyte colony-stimulating factor \\
CSF- $\beta$, CSF-3 & Colony-stinulating factor $\beta$ or 3, respectively \\
MGI-1G, MGI-2 & Macrophage/granulocyte inducer 1G or 2, respectively \\
G/M-CSA & Granulocyte/macrophage colony-stimulating activity \\
DF & Differentiation factor; pluripoietin \\
pCSF & Pluripotent colony-stimulating factor \\
GM-CSF, CSF-GM & Granulocyte/macrophage colony-stimulating factor \\
CSF- $\alpha$, CSF-2 & Colony-stimulating factor $\alpha$ or 2, respectively \\
MGI-1GM & Macrophage/granulocyte inducer lGM \\
Eo-CSF & Eosinophil colony-stimulating factor \\
HCGF & Hematopoietic cell growth factor \\
KTGF & Keratinocyte-derived T cell growth factor \\
NIF-T & T cell-derived neutrophil migration inhibition factor \\
\hline
\end{tabular}

Modified from Ibelgaufts.

TABLE 64.2. Commercial Formulations of G-CSF and GM-CSF.

\begin{tabular}{lll}
\hline Generic name & Trade name & \multicolumn{1}{c}{ Country } \\
\hline G-CSF & & \\
Filgrastim & Neupogen & $\begin{array}{l}\text { Europe, US, Canada, Australia } \\
\text { Japan, Taiwan, Korea, China }\end{array}$ \\
Lenograstim & $\begin{array}{l}\text { Neutrogin } \\
\text { Granocyte }\end{array}$ & $\begin{array}{l}\text { Japan, China } \\
\text { Europe, Australia }\end{array}$ \\
Nartograstin & Neu-Up & Japan \\
GM-CSF & & \\
Molgramostim & Leukomax & Europe, Canada \\
Sargramostim & Leukine & US \\
\hline
\end{tabular}

Modified from Root and Dale, ${ }^{2}$ with permission.

neutrophils from the bone marrow in response to an infectious challenge and were therefore more susceptible than controls to sublethal doses of infectivc agents.

Doses of G-CSF ranging from 1 to $60 \mu \mathrm{g} / \mathrm{kg} /$ day given to human volunteers for 6 days produced dose-dependent 1.8- to 12-fold increases in the absolute ncutrophil count. ${ }^{15}$ In a volunteer study, we found a dose-dependent increase of the polymorphonuclear neutrophil (PMN) count with a plateau lasting throughout the whole 12 days of treatment with G-CSF (filgrastim). Counts equal to those prior to treatment were secn 72 hour after the last injection, (unpublished observation: submitted for publication). Lesser increases in monocyte and lumphocyte counts have also been reported. ${ }^{16}$ In addition to increasing the pool of circulating neutrophils, G-CSF primes these immune cells for enhanced effector functions by improving the oxidative burst, phagocytosis, and chemotaxis and by extending their lifetime by delaying apoptosis. ${ }^{17-19}$ Thus G-CSF promotes the migration of increasing numbers of immunocompetent and highly potent neutrophils to the focus of infection in an effort to eradicate invading microbes.

Neutrophils pose the first line of defense against all particles identified as foreign; but they may cause damage to host tissues if they are activated prematurely or damaged or if the inflammatory reaction is not terminated on time ${ }^{20}$ Thus during the exploration of possible indications for G-CSF, it was necessary to consider whether the newly recruited neutrophils were functional or preactivated and whether application of G-CSF might unbalance the cytokine mediator network, resulting in exacerbation of the inflammatory reaction.

The in vitro studies discussed above showed that G-CSF does not directly activate but, rather, primes PMNs for increased responsiveness to subsequent stimulation. The implication of this priming effect of G-CSF on PMNs is that their functions are potentiated only in the case of stimulation by exogenous signals.

\section{Effects of G-CSF on the Humoral Response}

The inflammatory response is driven primarily by the cytokines tumour necrosis facor- $\alpha$ (TNF $\alpha$ ), interleukin-l (IL-l), and interferon- $\gamma$ (IFN $\gamma)$, which are produced by monocytes/macrophages and lymphocytes. Endogenous countermcasures include a reduction in their production or secretion and the release of their respective antagonists: soluble TNF receptors (sTNF-R) or IL-1 receptor antagonist (IL-1 ra).

In vitro and ex vivo experiments indicated that G-CSF adjusts the response of rodent and human mononuclear cells to immunostimulatory agents, such as the gram-negative cell wall

TABLE 64.3. Approved and Experimental Indications of G-CSF and GM-CSF.

\begin{tabular}{lll}
\hline Indication & \multicolumn{1}{c}{ G-CSF } & \multicolumn{1}{c}{ GM-CSF } \\
\hline Aplastic anemia & Approved in some countries & \\
Acute leukemia & Approved in some countries & Approved in some countries \\
Bone marrow transplantation & Approved & Approved \\
Chemotherapy-induced ncutropenia & Approved & Approved \\
Diabetic foot infection & Experinental (phase II) & \\
Fungal infection, candidemia & Experimental (phase II) & \\
Myclodysplastic syndrome & Approved in some countries & \\
Nonneutropenic infection & Experimental (phase II-III) & Approved in some countries \\
Neutropenia in HIV infection & Approved in some countries & Approved in some countries \\
Peripberal blood progenitor cell transplantation & Approved in most countries & \\
Severe chronic neutropenia & Approved & \\
\hline
\end{tabular}

Modificd from Frumkin and Dale, ${ }^{3}$ with permssion. 
component lipopolysaccharide (LPS), by causing a decrease in the production of proinflammatory cytokines and an increase in antiinflammatory cytokine release. ${ }^{21-23}$ These results were substantiated in a series of ex vivo human volunteer studies: Whole blood from G-CSF-treated volunteers responded to a variety of immunostimuli, such as LPS, preparations from grampositive bacteria, superantigens, or phorbol esters, with reduced TNF activity in comparison to blood from placebo-treated controls. ${ }^{24,25}$ Neutrophils from these G-CSF-treated volunteers showed increased ex vivo LPS-inducible IL-1 ra release, whereas the shedding of soluble TNF receptors was unaffected when calculated per PMN, though of course these cells were present in significantly higher numbers in the blood of the G-CSF-treated subjects. ${ }^{25}$ Furthermore, the release capacity of the chemoattractive leukotriene $B_{4}$, when expressed per neutrophil, was decreased significantly. This finding can be interpreted as a further antiinflammatory effect of G-CSF unrelated to the cytokine network (unpublished observations). In addition, IFN $\gamma$ formation by lymphocytes was attenuated in whole blood incubated in the presence of LPS. Thus the overall antiinflammatory effect of a single G-CSF injection consisted of the attenuated release of proinflammatory mediators by monocytes and lymphocytes and concomitant augmented formation and secretion of the respective antagonists by neutrophils.

In another study we examined the effects of daily G-CSF treatment for 12 days in 24 healthy volunteers. Compared to a placebo group, TNF $\alpha$, IL-12, and IFN $\gamma$ rclease in whole blood samples in response to ex vivo stimulation by LPS was reduced in the verum groups compared with the control group throughout treatment. Thus the antiinflammatory effect of G-CSF is also maintained under sustained treatment regimens. The in vitro addition of IL- 12 to LPS-stimulated blood lcssened the attenuation of IFN $\gamma$ and $\mathrm{TNF} \ddot{x}$ release capacity, indicating that suppression of IL- 12 release in pivotal is the antiinflammatory activity to G-CSF.

To assess the time window during which treatment with exogenous G-CSF might improve the coursc of an infection, a volunteer trial was held in which G-CSF was injected 2 or 24 hours before challenge with LPS in vivo. ${ }^{26}$ Administration of G-CSF shortly before LPS boosted the levels of TNF, IL-6, IL-8, IL-1 ra, and both kinds of s TNF-R. In comparison, G-CSF injection 1 day prior to challenge significantly decreased IL-8 levels and moderately attenuated the release of TNF and IL-6. The release of IL-1 ra and sTNF-R had increased prior to LPS injection. Administration of LPS resulted in a further increase in the sTNF-R I and II levels, whereas IL-1 ra release remained unaltered. Despite the different effects on cytokine release patterns, the two treatment regimens resulted in similar positive effects on neutrophil activation and similar changes in surface molecule expression. Moreover, both G-CSF pretreatments blocked LPS-induced granulocyte accumulation in the lung.

\section{G-CSF in Sepsis Models}

Many studies have becn performed in diverse animal models to explore the relevance of these observations during sepsis and septic shock and to determine whether unacceptable side effects are associated with G-CSF treatment of these conditions. The efficacy of G-CSF, alone or in combination with antibiotics, has been explored in a wide variety of nonneutropenic infectious disease models including neonatal sepsis, pneumonia, infections complicated by ethanol intoxication, burn wound infection, intraabdominal sepsis, and intramuscular infection. ${ }^{18,27}$ Results from these studies and those discussed below, in which the survival rate was increased significantly by G-CSF in most cases, indicated that prophylactic administration of G-CSF as a pretreatment when an increased risk of infection is foreseeable, (e.g., before an operation) may be beneficial prophylactically.

In all the animal studies discussed below, G-CSF treatment was initiated prior to or simultaneous with the infectious challenge. Results pertaining to the activity of neutrophils under G-CSF treatment in defense against infection were mostly uniformly positive: recruitment of neutrophils to the site of infection was improved in a pneumonia model ${ }^{28}$ and infections seemed to remain more localized in infections with Escherichia coli, through cecal ligation and puncture (CLP) or with subcutaneous injections, than in control animals ${ }^{29,30}$ as determined by histological evidence, myeloperoxidase activity, or glucose uptake in tissue adjacent to the site of infection. However, in a murine model where radionuclide-labeled $E$. coli were injected, no differences in the translocation through tissues were observed. $^{31}$ However, improved bactericidal activity was reported in each of these cases and in models of pneumonia and peritonitis. $^{32,33}$

Regarding cytokine levels during infection, TNF $\alpha$ serum levels in G-CSF-treated animals were reported to be decreased compared to levcls in controls in infection models in mice, rats and dogs. ${ }^{21,34-36}$ G-CSF-treated galactosamine-sensitized mice exhibited reduced IL-2 serum levels without an effect on TNF $\alpha$ release. ${ }^{37}$ Rabbits with immune complex colitis had lower levels of the proinflammatory leukotriene $\mathbf{B}_{4}$ and thromboxane $\mathbf{B}_{2}$, but levels of the antiinflammatory prostaglandin $\mathrm{E}_{2}$ were not affected. ${ }^{38}$

Apart from the general improvement in the course and outcome of infections, there is evidence that prophylactic treatment with G-CSF would be beneficial in the specific treatment of septic shock. G-CSF was shown to protect rodents against endotoxin-induced hepatotoxicity and shock ${ }^{21,39}$ and peritonitis-induced multiple organ failure and death. ${ }^{6,40} \mathrm{It}$ also improved cardiovascular function, endotoxin clearance, and survival in two canine models of septic shock. ${ }^{6,41}$

Neutrophils have been implicated as key mediators in the pathogenesis of acute lung injury due to sepsis or endotoxemia. Accordingly, deliberate augmentation of neutrophil production and activity might be deleterious in patients with sepsis. Several studies have addressed this issue by examining the effects of G-CSF treatment on acute lung injury in guinea pigs, ${ }^{42}$ pigs ${ }^{29,43}$ and sheep ${ }^{44}$ challenged with LPS. The data from these preclinical studies have been consistent in showing no evidence of exacerbation of lung injury as a consequence of treatment with G-CSF. 


\section{Use of G-CSF in Clinical Trials}

The benefits of G-CSF treatment in nonneutropenic animal models of infection provided a basis for clinical studies on the effects of G-CSF in regard to the incidence and course of infections that might result in sepsis. G-CSF proved to be safe in intensive care unit (ICU) and septic patients, ${ }^{10,45,46}$ who apparently also benefited from the therapy. Generation and function of neutrophils was improved in 20 postoperative/ posttraumatic patients at risk of sepsis or with sepsis who were given continuous infusions of G-CSF (filgrastim) for 7 days. Furthermore, IL-8 decreased in all six patients whose initial IL8 values were $>90 \mathrm{pg} / \mathrm{ml}$. IL-l ra increased in 10 patients, though there was no effect on the levels of TNF $\alpha$ or sTNF-R type I. ${ }^{47}$

When G-CSF treatment was commenced before an operation it significantly reduced the incidence of infectious complications in 19 cancer patients undergoing esophagectomy compared with 77 control patients. ${ }^{7}$ G-CSF reduced the incidence of multiple organ failure in 756 pneumonia patients ${ }^{48}$ and 37 liver allograft recipients. ${ }^{49}$

In conclusion, G-CSF showed antiinflammatory effects combined with improved host defense, not only in preclinical models but also in the clinical setting. Previous clinical experience has shown that the use of G-CSF is associated with a very low incidence of side effects, except mild bone pain. Therefore further trials of G-CSF given for prophylaxis of sepsis and septic complications are ratified, and widespread use of G-CSF in this setting might be considered a clinical option in the near future.

\section{GM-GSF}

The initial phase of the systemic inflammatory response syndrome (SIRS) is characterized by excessive production of proinflammatory cytokines by monocytes/macrophages and is therefore termed the hyperinflammatory phase. ${ }^{50}$ Here, antiinflammatory therapy (e.g., anti-TNF antibodies, IL-lra, IL-10) was proposed as the appropriate measure. ${ }^{51}$ However, it has been found that this initial phase is followed by a so-called hypoinflammatory phase, also termed immune paralysis. ${ }^{52,53}$ Many patients who survive the acute hyperinflammation owing to intensive medical care succumb to subsequent infections. In such patients a drastic change in monocytc activity was observed (i.e., in vitro): The monocytes are no longer able to respond to an inflammatory stimulus such as LPS with secretion of proinflammatory cytokines (e.g., TNF $\alpha$ ). ${ }^{52,54.59}$ The longer this state of immunc paralysis continues, the more adverse is the prognosis. ${ }^{52,56}$ Secondary infections during the condition of immune paralysis (i.e., when the organism's state of defense is insufficient) often determine the fate of a patient during septic multiple organ failure.

Therefore a therapeutic goal consists in the reconstitution of immune competence during the late phase of septic shock. For such an indication, immune stimulation with GM-CSF seems to represent a promising pharmacologic therapcutic principle. GM-CSF is a pluripotent hematopoietic growth factor involved in regulating the proliferation, differentiation, and mature functions of granulocytes and monocytes; macrophages, ${ }^{60}$ the two key cell types of the nonspeciliic immune system. GM-CSF has been used to accelerate recovery of the granulocyte and monocyte counts after chemotherapy or bone marrow transplantation, thereby reducing the risk of infections from bacterial or fungal sources due to leukopenia. ${ }^{61-64}$

\section{Role of Endogenous GM-CSF}

The role of GM-CSF in vivo became evident in knockout animals. Mice with homozygous mutations of the GM-CSF gene showed no major deficits in hematopoiesis until 12 weeks of age, but they developed abnormal lungs and some suffered from subclinical bacterial or fungal infection. ${ }^{65}$ These observations indicate that GM-CSF is not essential for maintenance of hematopoietic cells and their precursors but, rather, for normal pulmonary physiology and resistance to local infection. This conclusion was supported by the finding that the administration of neutralizing monoclonal antibodics specific for GM-CSF to Cryptococcus neoformans-infected normal mice increased mortality and induced rapid progresssion of the disease. ${ }^{66}$

To explore further the in vivo role of GM-CSF in infection, GM-CSF knockout mice were treated with endotoxin (LPS). Hypothermia and loss of body weight were markedly attenuated in LPS-treated GM-CSF-deficient mice compared with similarly treated control mice. Moreover, the levels of the circulating proinflammatory cytokines IFN $\gamma, \mathrm{ILl} \alpha$, and IL-6 were lower in LPS-treated GM-CSF-deficient mice than in LPS-treated control mice. Peak levels of TNF $\alpha$ in response to LPS treatment were the same in the serum of all the mice, but TNF $\alpha$ persisted longer in GM-CSF-deficient mice. LPS-stimulated peritoneal macrophages from GM-CSF-deficient mice produced significantly less IL- $l \alpha$ and nitric oxide than macrophages from wild-type mice, although there was no difference in TNF $\alpha$ production in vitro. These results indicate that GM-CSF contributes to cytokine production in LPS-mediated septic shock and that the attenuated production of these secondary cytokines (IFN $\gamma$, IL- $1 \alpha$, and IL-6) may contribute to the endotoxinresistant phenotype of GM-CSF-deficient mice. ${ }^{67}$

\section{GM-CSF as an Immunostimulatory Drug}

The initiation of host defense in the form of an inflammatory reaction is mediated primarily by the cytokines TNF $\alpha$ and IL-1 ${ }^{68-74}$ GM-CSF was found to potentiate LPS-induced TNF $\alpha$ and $\mathrm{IL}-1$ production of murine and human monocytic cells. ${ }^{58,75-77} \mathrm{We}$ also found that GM-CSF is a potent enhancer of LPS-induced TNF $\alpha$ production in vivo in normal and experimentally immunocompromised (LPS-desensitized) mice. ${ }^{78}$ Furthermore, in vitro and ex vivo experiments revealed that LPS-induced IL-1 release from bone marrow or spleen cells was also enhanced in GM-CSF-treated mice. ${ }^{107}$ 


\section{GM-CSF Production: Strictly Controlled}

GM-CSF is not detectable in the circulation of healthy animals or humans, though it may be found in the major organs at low concentrations. ${ }^{79}$ Only small amounts of GM-CSF were measured in the serum of mice infected with Listeria monocytogenes. ${ }^{80}$ Patients with experimental endotoxemia, ${ }^{81}$ neutropenic fever, ${ }^{82}$ or even sepsis ${ }^{83}$ also do not normally have elevated serum GMCSF levels. In patients with meningococcemia GM-CSF concentrations higher than $1 \mathrm{ng} / \mathrm{ml}$ were only briefly present in subjects with life-threatening septic shock and were strongly associated with fulminant infection. ${ }^{6}$

As no systemic GM-CSF levels can be detected in patients with infection, endogenous GM-CSF is thought to play its physiologic role in the immediate vicinity of the cells by which it is secreted. ${ }^{84,85}$ The hypothesis is supported by the observation that in patients with meningitis only cerebrospinal fluid contained a measurable concentration of GM-CSF. ${ }^{86}$

In summary, it appears that the body highly restricts production of the powerful immunostimulator GM-CSF. Therefore it is not surprising that rats who underwent GLP with sepsis-induced organ injury, when given rmGM-CSF, showed no increased survival rates but, rather, earlier deaths than the control group. Early leukosequestration to the peritoneal cavity was inhibited, and severe liver injuries were observed, ${ }^{87}$ that might have resulted from the stimulating activity of GM-CSF on the expression of TNF. One study found that survival in two mouse models of gut-derived sepsis was improved by pretreatment with GM-CSF because of better gut barrier function and better bacterial clearance. ${ }^{88}$ However, we found that prophylactic administration of rmGM-CSF neither augmented leukocyte numbers nor protected mice from lethal fecal peritonitis. ${ }^{14}$ Consequently, systemic application of GMCSF may be detrimental if given before or during the proinflammatory phase of sepsis. ${ }^{108}$

\section{GM-CSF in Models of}

\section{Impaired Immune Competence}

A number of studies have been performed in which neonatal rats (which are more vulnerable to infection than older animals) or animals first made susceptible to infection by trauma, burn, or myelosuppression were treated with exogenous GM-GSF and subsequently challenged by CLP or inoculation of infective agents. These studies may be considered models for the diminished status of the immune system experienced at the hypoinflammatory stage of sepsis.

Neonatal rats were found to have deficient PMN production and function during infection. Prophylactic rmGM-CSF given intraperitoneally 6 hours before a 90\% lethal dose challenge with Staphylococcus aureus significantly improved survival in a neonatal rat model of infection. ${ }^{89}$ In another study, neonatal rats with streptococcal sepsis were given rhGM-CSF after infection. A higher survival rate than in control animals not given rhGM-GSF was reported, apparently due to phagocyte priming or cellular influx into the peritoneum (or both), ${ }^{90}$ even though human GM-GSF is generally believed not to be bioactive in mice. Furthermore, GM-CSF administered in conjunction with penicillin to neonatal rats with established group B streptococcal infection decreased the mortality rate substantially in comparison to penicillin alone. ${ }^{91}$

Mice made susceptible to infection by trauma were treated with GM-CSF for 5 days before induction of peritoniis. These mice had a significantly higher survival rate than control mice, which underwent the same regimen but received placebo instead of GM-CSF. Peritoneal cell yields were increased in the GM-CSF group, and harvested macrophages stimulated with phorbol ester released larger amounts of both superoxide anion and TNF and less nitric oxide than mice in the control group. ${ }^{92}$

In a murine model $20 \%$ surface burns plus CLP were applied. Survival was significantly better on day 10 after injury in animals treated with GM-CSF on days 5-9 after the burn. ${ }^{93}$ Concanavalin A-stimulated $\mathbf{T}$ cell proliferation and IL-2 production, which were suppressed after burn injury, were also improved by treatment with GM-CSF. ${ }^{93}$

The infection of GM-CSF-pretreated, myelosuppressed mice with normally lethal doses of Pseudomonas aeruginosa, Staphylococcus aureus, or Candida albicans resulted in a significant dose-dependent improvement of survival. ${ }^{94,95}$ There has also been research on combinations of GM-CSF with IL-6 or leukemia inhibitory factor (LIF), which are both potent inducers of the acute-phase response and can induce an increase in the platelet count. ${ }^{95}$ The rationale for these combinations was that the synergism of the induction of opsonization of microorganisms by acute-phase proteins with activation of phagocytes by GM-CSF should increase resistance to infections. This hypothesis was proven correct when myelosuppressed mice were treated with either of the combinations and infected with Pseudomonas aeruginosa. ${ }^{96}$

Preclinical studies with recombinant human GM-CSF are limited by the lack of cross-species reactivity in mice. ${ }^{97}$ The protein sequence homology between human and murine GM-CSF is only $60 \%{ }^{98}$ Human GM-CSF does not affect canine PMNs in vitro; ${ }^{99}$ and even in monkeys only-short-term studies can be undertaken because antibodies develop to human GM-CSF. ${ }^{62}$ However, because of the dangers associated with immune stimulation, volunteer studies may be considered unethical. We have taken advantage of a dose-finding study of GM-CSF for wound healing of basalioma, where we investigated the change in white blood cell count and the cytokine production pattern ex vivo in blood from patients treated with low doses of GM-CSF. Patients responded to the treatment with a general leukocytosis, though only the eosinophil fraction was significantly increased relative to the other populations. Cytokine secretion from GM-CSFtreated patients in response to either LPS or lipoteichoic acid was characterized by decreased IFN $\gamma$ and increased IL-10 and IL-I ra secretion and can therefore basically be considered an antiinflammatory reaction. Side effects were also relatively mild (unpublished observation; submitted for publication). 
These results indicate that leukocytosis can be initiated by low doses of GM-CSF, with which the proinflammatory priming, observed in vitro and in animal models at higher doses, is replaced by a trend toward an antiinflammatory cytokine pattern.

\section{Potential Application of GM-CSF for Human Sepsis}

Although monocytes from septic shock patients exhibit greater baseline respiratory burst activity than monocytes from healthy subjects, the response to secondary stimulation with bacterial stimuli is attenuated. ${ }^{100}$ GM-CSF restored the ability of monocytes to respond appropriately to secondary stimulation. Expression of certain integrin adhesion molecules, CD62L, and Fc $\gamma$ receptors was increased on monocytes of septic shock patients; expression of CDI lc was reduced. GM-CSF upregulated integrin expression and decreased CD62L, CD32, and CD 16 expression. Priming monocytes with GM-CSF accelerated tissue factor activation following stimulation with LPS and bacterial culture supernatant. ${ }^{100}$

When a high dose $\left(750 \mu \mathrm{g} / \mathrm{m}^{2}\right.$ day IV) of GM-CSF was administered to sarcoma patients with neutropenia for 2 weeks, no increase in basal release of TNF $\alpha$ or IL-1 $\beta$ by monocytes ex vivo was found, though the LPS-stimulated release of both factors reached 8 -fold and 10 -fold their respective values on day $0 .{ }^{101}$ A single dose $(2.5,5.0$, or $10.0 \mu \mathrm{g} / \mathrm{kg})$ of GM-CSF resulted in a significant increase of in vivo plasma levels of IL-I ra and a trend toward increased IL-8 levels in cancer patients. ${ }^{102}$ A case has been reported where a patient in the ICU with acquired agranulocytosis and sepsis experienced rapid neutrophil recovery and resolution of a clinical infection when treated with GM-CSF. ${ }^{103}$

\section{Possible Adverse Effects}

In humans, systemic administration of GM-CSF at doses sufficient to produce plasma levels comparable to endogenous levels seen during severe meningcoccal septic shock induced vasodilatation, hypotension, and hypoxia. ${ }^{6}$ In a model where GM-CSF was highly expressed in rat lung after intrapulmonary transfer of the gene coding for murine GM-CSF using an adenoviral vector, a sustained but self-limiting accumulation of eosinophils and macrophages was associated with tissue injury in the lung followed by varying degrees of irreversible fibrotic reactions observed at later stages, suggesting that GM-CSF plays a role in the development of respiratory conditions characterized by eosinophilia, granuloma, or fibrosis. ${ }^{104}$ Increases in plasma GM-CSF in patients with inflammatory disorders such as asthma ${ }^{86}$ or granulocytosis due to infection ${ }^{105}$ indicate that GM-CSF should be used with caution in patients with respiratory diseases. However, in a patient with $\mathrm{T}$ lymphocytosis with gramulocytopenia and severe perianal infection, the eosinophilia initiated by GM-CSF $(12.5 \mu \mathrm{g} / \mathrm{kg}$ for 8 days) correlated with improvement of the perianal ulceration. ${ }^{106}$

\section{Conclusions}

A number of studies have indicated that the immunostimulator properties of GM-CSF may be beneficial in reconstituting the compromised immune system, thereby improving the outcome after secondary infections or sepsis.

\section{References}

1. Ibelgaufts H: Lexikon der Zytokine, München: Medikon Verlag, 1992.

2. Root RK, Dale DC: G-CSF and GM-CSF: comparisons and potential for use in the treatment of infections in non-neutropenic patients. J Inf Dis 1999;149:5342-5352.

3. Frumkin LR, Dale DC: The role of colony-stimulating factors in HIV disease. AIDS Reader 1996;6:185-193.

4. Kawakami M, Tsutsumi H, Kamakawa T, et al: Levels of serum granulocyte colony-stimulating factor in patients with infections. Blood 1990; 76:1962-1964.

5. Kragsbjerg $P$, Jones I, Vikerfors $T$, et al: Diagnostic value of blood cytokine concentrations in acute pneunonia. Thorax 1995;50:1253-1257.

6. Waring PM, Presneill J, Maher DW, et al: Differential alterations in plasma colony-stimulating factor concentrations in meningococcaernia. Clin Exp Immunol 1995; 102:501-506.

7. Mansmann G, Engert A, Hübel K: Application of G-CSF in the nonneutropenic host. Onkologie 1998;21:124-127.

8. Kragsbjerg P, Holmberg $H$, Vikerfors $T$ : Dynamics of blood cytokine concentrations in patients with bacteremic infections. Scand J Infect Dis 1996;28:391-398.

9. Tanaka $\mathrm{H}$, Ishikawa $\mathrm{K}$, Nishino $\mathbf{M}$, et al: Changes in granulocyte colony-stimulating factor concentration in patients with trauma and sepsis. J Trauma 1996;40:718-725.

10. Gross-Weege W, Weiss M, Schneider M, et al: Safety of a lowdosage Filgrastim (rhG-CSF) treatment in non-neutropenic surgical intensive care patients with an inflammatory process. Intensive Care Med 1997;23:16-22.

11. Stoltz DA, Bagby GJ, Nelson S: Use of granulocyte colonystimulating factor in the treatment of acute infectious diseases. Curr Opin Hematol 1997;4:207-212.

12. Licschke GJ, Burgess AW: Granulocyte colony-stimulating factor and granulocyte-macrophage colony-stimulating factor (1). N Engl J Med 1992;327:28-35.

13. Lieschke GJ, Grail D, Hodgson G, et al: Mice lacking granulocyte colony-stimulating factor have chronic neutropenia, granulocyte and macrophage progenitor cell deficiency, and impaired neutrophil mobilization. Blood 1994;84:1737--1746.

14. Barsig J, Bundschul DS, Hartung $T$, et al: Control of fecal peritoneal infection in mice by colony-stimulating factors. $J$ Infect Dis $1996 ; 174: 790-799$.

15. Dale DC: Potential role of colony-stimulating factors in the prevention and treatment of infectious diseases. Clin Infect Dis 1994;18 (Suppl 2):S180-S188.

16. Hartung $\mathrm{T}$ : Immunomodulation by colony-stimulating factors. Rev Physiol Biochem Pharmacol 1999;136:1-164.

17. Demetri GD, Griffin JD: Granulocyte colony-stimulating factor and its receptor. Blood 1991;78:2791-2808.

18. Dale DC, Liles WC, Summer WR, et al: Review: granulocyte colony-stimulating factor-role and relationships in infectious diseases. J Infect Dis 1995;172:1061-1075. 
19. Hartung $T$, Wendel A: Immunomodulatory properties of Filgrastim ( $r$-metHuG-CSF) in preclinical models. In: Morstyn G, et al (eds) Filgrastim (r-metHuG-CSF) in Clinical Practice. New York, Marcel Dekker, 1998;397-427.

20. Smith JA: Neutrophils, host defense, and inflammation: a doubleedged sword. J Leukoc Biol 1994;56:672-686.

21. Görgen I, Hartung T, Leist $M$, et al: Granulocyte colonystimulating factor treatment protects rodents against lipopolysaccharide-induced toxicity via suppression of systemic tumor necrosis factor-alpha. J Immunol 1992; 149:918-924.

22. Kitabayashi A, Hirokawa M, Hatano Y, et al: Granulocyte colony-stimulating factor downregulates allogeneic immune responses by posttranscriptional inhibition of tumor necrosis factoralpha production. Blood 1995;86:2220-2227.

23. Pan L, Delmonte J Jr, Jalonen CK, et al: Pretreatment of donor mice with granulocyte colony-stimulating factor polarizes donor $T$ lymphocytes toward type- 2 cytokine production and reduces severity of experimental graft-versus-host disease. Blood 1995;86:4422 4429 .

24. Hartung T, Volk H-D, Wendel A: G-CSF: an anti-inflammatory cytokine. J Endotoxim Res 1995;2:195-201.

25. Hartung T, Docke WD, Gantner F, et al: Effect of granulocyte colony-stimulating factor treatment on ex vivo blood cytokine response in human volunteers. Blood 1995;85:2482-2489.

26. Pajkrt D, Manten A, van der Poll T, et al: Modulation of cytokine release and neutrophil function by granulocyte colony-stimulating factor during endotoxemia in humans. Blood 1997;90: 1415-1424.

27. Nelson S: Role of granulocyte colony-stimulating factor in the immune response to acute bacterial infection in the nonneutropenic host: an overview. Clin Infect Dis 1994;18(Suppl 2):S197-S204.

28. Lister PD, Gentry MJ, Preheim LC: Granulocyte colony-stimulating factor protects control rats but not ethanol-fed rats from fatal pneumococcal pneumonia. J Infect Dis 1993;168:922--926.

29. Patton JHJ, Lyden SP, Ragsdale DN, et al: Granulocyte colonystimulating factor improves host defense to resuscitated shock and polymicrobial sepsis without provoking gencralized neutrophilmediated damage. J Trauma 1998;44:750-758.

30. Lang CH, Bagby GJ, Dobrescu C, et al: Effect of granulocyte colony-stimulating factor on sepsis-induced changes in neutrophil accumulation and organ glucose uptake. J Infect Dis 1992;166:336-343.

31. Eaves-Pyles T, Alexander JW: Granulocytc colony-stimulating factor enhances killing of translocated bacterial but does not affect barrier function in a burn mouse model. J Trauma 1996;41: 1013-1017.

32. Dunne JR, Dunkin BJ, Nelson S, et al: Effects of granulocyte colony stimulating factor in a nonneutropenic rodent model of Escherichia coli peritonitis. J Surg Res 1996;61:348-354.

33. Zhang P, Bagby GJ, Stoltz DA, et al: Enhancement of peritoneal leukocyte function by granulocyte colony-stimulating factor in rats with abdominal sepsis. Crit Care Med 1998;26:315-321.

34. Eichacker PQ, Waisman Y, Natanson C, et al: Cardiopulmonary effects of granulocyte colony-stimulating factor in a canine model of bacterial sepsis. J Appl Physiol 1994;77:2366-2373.

35. Lorenz W, Reimund KP, Weitzel F, et al: Granulocyte colonystimulating factor prophylaxis before operation protects against lethal consequences of postoperative peritonitis. Surgery 1994;1 16:925-934.

36. Lundblad R, Nesland JM, Giercksky KE: Granulocyte colonystimulating factor improves survival rate and reduces concentra- tions of bacteria, endotoxin, tumor necrosis factor, and endothelin- 1 in fulminant intro-abdominal sepsis in rats. Crit Care Med 1996;24:820-826.

37. Aoki Y, Hiromatsu K, Kobayashi N, et al: Protective effect of granulocyte colony-stimulating factor against T-cell-meditated lethal shock triggered by superantigens. Blood 1995;86: 1420-1427.

38. Hommes DW, Meenan J, Dijkhuizen S, et al: Efficacy of recombinant granulocyte colony-stimulating factor (rhG-CSF) in experimental colitis. Clin Exp Immunol 1996;106:529-533.

39. Vollmar B, Messner S, Wanner G, et al: Immunomodulatory action of G-CSF in a rat model of endotoxin-induced liver injury: an intravital microscopic analysis of Kupffer cell and leukocyte response. J Leukoc Biol 1997;62:710-718.

40. O'Reilly M, Silver GM, Greenhalgh DG, et al: Treatment of intra-abdominal infection with granulocyte colony-stimulating factor. J Trauma 1992;33:679-682.

41. Freeman BD, Quezado Z, Zeni F, et al: rG-CSF reduces endotoxemia and improves survival during $E$. coli pneumonia. J Appl Physiol 1997;83:1467-1475.

42. Kanazawa M, Ishizaka A, Hasegawa N, et al: Granulocyte colonystimulating factor does not enhance endotoxin-induced acute lung injury in guinea pigs. Am Rev Respir Dis 1988;148:10301035.

43. Fink MP, O'Sullivan BP, Menconi MJ, et al: Effect of granulocyte colony-stimulating factor on systemic and pulmonary responses to endotoxin in pigs. J Trauma 1993;34:571-577.

44. Silver GM, Fink MP: Possible roles for anti- or pro-inflammatory therapies in the management of sepsis. Surg Clin North Am 1994;74:711-723.

45. Endo $S$, Inada $K$, Inoue $Y$, et al: Evaluation of recombinant human granulocyte colony-stimulating factor (rhG-CSF) therapy in granulopoietic patients complicated with sepsis. Curr Med Res Opin 1994;13:233-241.

46. Weiss M, Gross-Weege W, Schneider M, et al: Enhancement of neutrophil function by in vivo filgrastim treatment for prophylaxis of sepsis in surgical intensive care patients. J Crit Care 1995; 10:21-26.

47. Weiss M, Gross-Weege W, Harms B, et al: Filgrastim (RHG$\mathrm{CSF}$ ) relatcd modulation of the inflammatory response in patients at risk of sepsis or with sepsis. Cytokine 1996;8:260-265.

48. Andresen J, Movahhed H, Nelson S: Filgrastim (r-metHuG-CSF) in pneumonia. In: Morstyn G, et al (ed) Filgrastim ( $r$-metG-CSF) in Clinical Practice. New York, Marcel Dekker, 1998;429-446.

49. Foster PF, Mital D, Sankary HN, et al: The use of granulocyte colony-stimulating factor after liver transplantation. Transplantation 1995;59:1557-1563.

50. Bone RC: Toward a theory regarding the pathogenesis of the systemic inflammatory response syndrome: what we do and do not know about cytokine regulation. Crit Care Med 1996;24: 163-172.

51. Volk HD, Reinke $P$, Krausch $D$, et al: Monocyte deactivation-rationale for a new therapeutic strategy in sepsis. Intensive Care Med 1996;22(Suppl 4):S474-S481.

52. Döcke W-D, Syrbe U, Meinecke A, et al: Improvement of monocytic function-a new therapeutic approach? In: Reinhart $\mathbf{K}$, Eyrich $\mathbf{K}$, Sprung $\mathbf{C}$ (ed) Update in Intensive Care and Emergency Medicine. Sepsis - Current Perspectives in Pathophysiology and Therapy, vol 18. Berlin, Springer, 1994:473-500.

53. Von Baehr R, Lohmann T, Heym S, et al: Immunoparalysis in case of septicaemia. Z Klin Med 1990;45:1133-1137. 
54. Faist E, Mewes A, Baker CC, et al: Prostaglandin $\mathrm{E}_{2}\left(\mathrm{PGE}_{2}\right)-$ dependent suppression of interleukin (IL-) 2 production in patients with major trauma. J Trauma 1987;27:837-848.

55. Faist E, Mewes A, Strasser T, et al: Alterations of monocyte function following major injury. Arch Surg 1988;123: 287-292.

56. Munoz C, Carlet J, Fitting C, et al: Dysregulation of in vitro cytokine production by monocytes during sepsis. J Clin Invest $1991 ; 88: 1747-1754$.

57. Volk HD, Thieme M, Ruppe U, et al: Alterations in function and phenotype of monocytes from patients with septic disease: predictive value and new therapeutic strategies. $Z$ Kiln Med 1990;45:1 133-1137.

58. Randow F, Döcke W-D, Bundschuh DS, et al: In vitro prevention and reversal of lipopolysaccharide desensitization by IFN- $\gamma$, IL-12, and granulocyte-macrophage colony-stimulating factor. J Immunol 1997;158:2911-2918.

59. Ertel W, Kremer JP, Kenney J, et al: Downregulation of proinflammatory cytokine release in whole blood from septic patients. Blood 1995;85:1341-1347.

60. Gabrilove JL, Jakubowski A: Hematopoietic growth factors: biology and clinical application. J Natl Cancer Inst Monogr 1990;10:73-77.

61. Scarffe JH: Emerging clinical uses for GM-CSF. Eur J Cancer 1991;27:1493-1504.

62. Morstyn G, Lieschke GJ, Sheridan W, et al: Pharmacology of the colony-stimulating factors. Trends Pharmacol Sci 1989;10: 154-159.

63. Whetton $\mathrm{AD}$ : The biology and clinical potential of growth factors that regulate myeloid cell production. Trends Pharmacol Sci 1990;11:285-289.

64. Moore MA: The clinical use of colony stimulating factors. Annu Rev Immunol 1991;9:159-191.

65. Stanley E, Lieschke GJ, Grail D, et al: Granulocyte/macrophage colony-stimulating factor-deficient mice show no major perturbation of hematopoiesis but develop a characteristic pulmonary pathology. Proc Natl Acad Sci USA 1994;91:5592-5596.

66. Collins HL, Bancroft GJ: Cytokine enhancement of complementdependent phagocytosis by macrophages: synergy of tumor necrosis factor-alpha and granulocyte-macrophage colonystimulating factor for phagocytosis of Cryptococcus neoformans. Eur J Immunol 1992;22:1447-1454.

67. Basu S, Dunn AR, Marino MW, et al: Increased tolerance to endotoxin by granulocyte-macrophage colony-stimulating factordefecient mice. J Immunol 1997;159:1412-1417.

68. Dinarello CA: Interleukin-l: amino acid sequences, multiple biological activities and comparison with tumor necrosis factor (cachectin). Year Immunol 1986;2:68-89.

69. Dinarello GA: An update on human interleukin-1: from molecular biology to clinical relevance. J Clin Immunol 1985;5: 287-297.

70. Bone RC, Balk RA, Cerra FB, et al: Definitions for sepsis and organ failure and guidelines for the use of innovative therapies in sepsis: the ACCP/SCCM Consensus Conference Committee, American College of Chest Physicians/Society of Critical Care Medicine. Chest 1992;101:1644-1655.

71. Tracey KJ, Beutler B, Lowry SF, et al: Schock and tissue injury induced by recombinant human cachectin. Science 1986; 234:470-474.

72. Tracey KJ, Cerami A: Tumor necrosis factor: an updated review of its biology. Crit Care Med 1993;21:S415-S422.
73. Damas $P$, Reuter A, Gysen $P$, et al: Tumor necrosis factor and interleukin-1 serum levels during severe sepsis in humans. Crit Care Med 1989;17:975-978.

74. Debets JM, Kampmeijer R, van der Linden MP, et al: Plasmä tumor necrosis factor and mortality in critically ill septic patients. Crit Care Med 1989;17:489-494.

75. Cannistra SA, Vellenga E, Groshek $P$, et al: Human granulocytemonocyte colony-stimulating factor and interleukin 3 stimulate monocyte cytotoxicity through a tumor necrosis factor-dependent mechanism. Blood 1988;71:672-676.

76. Sisson SD, Dinarello CA: Production of interleukin-l alpha, interleukin-l beta and tumor necrosis factor by human mononuclear cells stimulated with granulocyte-macrophage colonystimulating factor. Blood 1988;72:1368-1374.

77. Cohen L, David B, Cavaillon JM: Interleukin-3 enhances cytokine production by LPS-stimulated macrophages. Immunol Lett 1991;28:121-126.

78. Bundschuh DS, Barsig J, Hartung $T$, et al: Granulocytemacrophage colony-stimulating factor and IFN- $\gamma$ restore the systemic TNF- $\alpha$ response to endotoxin in lipopolysaccharidedesensitized mice. J Immun 1997;158:2862-2871.

79. Metcalf $D$ : The role of the colony-stimulating factors in resistance to acute infections. Immunol Cell Biol 1987;65:35-43.

80. Cheers C, Haigh AM, Kelso A, et al: Production of colonystimulating factors (CSFs) during infection: separate determinations of macrophage-, granulocyte-, granulocyte-macrophage-, and multi-CSFs. Infect Immun 1988;56:247-251.

81. Granowitz EV, Porat $R$, Orencole SF, et al: Granulocytemacrophage colony-stimulating factor synthesis during experimental endotoxemia in humans [letter, comment]. J Infect Dis 1992;166:1204-1205.

82. Gebon J, Layton JE, Maher D, et al: Endogenous haemopoietic growth factors in neutropenia and infection. $\mathrm{Br} \mathrm{J}$ Haematol 1994;86:265-274.

83. Gebon J, Layton JE, Maher D, et al: Endogenous haemöpoietic growth factors in neutropenia and infection. $\mathrm{Br} \mathrm{J}$ Haematol 1994;86:265-274.

84. Gasson JC: Molecular physiology of granulocyte-macrophage colony-stimulating factor. Blood 1991;77:1131-1145.

85. Freund M, Kleine HD: The role of GM-CSF in infection. Infection 1992;20 (Suppl 2):S84-S92.

86. Sallerfors B: Endogenous production and peripheral blood levels of granulocyte-macrophage (GM-) and granulocyte (G-) colonystimulating factors. Leuk Lymphoma 1994;13:235-247.

87. Toda H, Murata A, Oka Y, et al: Effect of granulocytemacrophage colony-stimulating factor on sepsis-induced organ injury in rats. Blood 1994;83:2893-2898.

88. Gennari R, Alexander JW, Gianotti L, et al: Granulocyte macrophage colony-stimulating factor improves survival in two models of gut-derived sepsis by improving gut barrier function and modulating bacterial clearance. Ann Surg 1994;220:68-76.

89. Frenck RW, Sarman G, Harper TE, et al: The ability of recombinant murine granulocyte-macrophage colony-stimulating factor to protect neonatal rats from septic death due to Staphylococcus aureus. J Infect Dis 1990;162:109-114.

90. Wheeler JG, Givner LB: Therapeutic use of recombinant human granulocyte-macrophage colony-stimulating factor in neonatal rats with type III group B streptococcal sepsis. J Infect Dis 1992; 165:938-941.

91. Givncr LB, Nagaraj SK: Hyperimmune human IgG or recombinant human granulocyte-macrophagc colony-stimulating factor 
as adjunctive therapy for group B streptococcal sepsis in newborn rats. J Pediatr 1993;122:774-779.

92. Austin OM, Redmond HP, Watson WG, et al: The beneficial effects of immunostimulation in posttraumatic sepsis. J Surg Res 1995;59:446--449.

93. Molloy RG, Holzheimer R, Nestor $M$, et al: Granulocytemacrophage colony-stimulating factor modulates immune function and improves survival after experimental thermal injury. $\mathrm{Br} \mathrm{J}$ Surg 1995;82:770-776.

94. Tanaka T, Okamura S, Okada $\mathrm{K}$, et al: Protective effect of recombinant murine granulocyte-macrophage colony-stimulating factor against Pseudomonas aenuginosa infection in leukocytopenic mice. Infect Immun 1989;57:1792-1799.

95. Liehl E, Hildebrandt J, Lam C, et al: Prediction of the role of granulocyte-macrophage colony-stimulating factor in animals and man from in vitro results. Eur J Clin Microbiol Infect Dis 1994;13(Suppl 2):S9-S17.

96. De Clerck F, De Brabander M, Neels H, et al: Direct evidence for the contractile capacity of endothelial cells. Thromb Res 1981;23:505-520.

97. Metcalf $\mathrm{D}$ : The molecular biology and functions of the granulocyte-macrophage colony-stimulating factors. Blood 1986; 67:257-267.

98. Wong GG, Witek JS, Temple PA, et al: Human GM-CSF: molecular cloning of the complementary DNA and purification of the natural and recombinant proteins. Science 1985;228:810-815.

99. D'Alesandro MM, Gruber DF, O'Halloran $\mathrm{KP}$, et al: In vitro modulation of canine polymorphonuclear leukocyte function by granulocyte-macrophage colony stimulating factor. Biotherapy 1991;3:233-239.

100. Williams MA, White SA, Miller J, et al: Granulocytemacrophage colony-stimulating factor induces activation and restores respiratory burst activity in monocytes from septic patients. J Infect Dis 1998;177:107-115.

101. Perkins RC, Vadhan-Raj S, Scheule RK, et al: Effects of continuous high dose rhGM-CSF infusion on human monocyte activity. Am J Hematol 1993;43:279-285.

102. Aman MJ, Stockdreher K, Thews A, et al: Regulation of immunomodulatory functions by granulocyte-macrophage colony-stimulating factor and granulocyte colony-stimulating factor in vivo. Ann Hematol 1996;73:231-238.

103. Weiss J, Elsbach P, Shu C, et al: Human bactericidal/permeability-increasing protein and a recombinant $\mathrm{NH}_{2}$-terminal fragment cause killing of serum-resistant gram-negative bacteria in whole blood and inhibit tumor necrosis factor release induced by the bacteria. J Clin Invest 1992;90:1122-1130.

104. Xing Z, Ohkawara X, Jordana M, et al: Transfer of granulocytemacrophage colony-stimulating factor gene to rat lung induces eosinophilia, monocytosis, and fibrotic reactions. J Clin Invest 1996;97:1102-1110.

105. Omori F, Okamura S, Shimoda $\mathbf{K}$, et al: Levels of human serum granulocyte colony-stimulating factor and granulocyte-macrophage colony-stimulating factor under pathological conditions. Biotherapy 1992;4:147-153.

106. Krieger G, Kneba $\mathbf{M}$, Vehmeyer $\mathrm{K}$, et al: Use of recombinant human granulocyte-macrophage colony stimulating factor in T-lymphocytosis with granulocytopenia. Eur J Haematol 1990; 44:205-206.

107. Tiegs G, Barsig J, Matiba B, et al: Potentiation by granulocyte macrophage colony-stimulating factor of lipopolysaccharide toxicity in mice. J Clin Invest 1994;93:2616-2622.

108. Hartung T, Doecke WD, Bundschuh D, et al: Effect of filgrastim treatment on inflammatory cytokines and lymphocyte functions. Clin Pharmacol Ther 1999;66:415-424. 